\title{
Effect of SnS thin film on the performance of porous silicon photodiode
}

\author{
${ }^{1}$ Ahmed N. Abd, ${ }^{2}$ Wasna'a M. Abdulridha, ${ }^{1}$ Mohammed O. Dawood \\ ${ }^{1}$ Physics Department, Science Faculty, University of Al- Mustansiriyah, Baghdad, Iraq \\ ${ }^{2}$ Basic Science Department, University of Al- Kufa, Najaf, Iraq \\ Corresponding author, E-mail: ahmed_naji_abd@yahoo.com
}

Keywords: Tin sulfide, Thin films, Photovoltaic materials, Thermal evaporation, Optical properties.

\begin{abstract}
In this study, Al/SnS/PS/n-Si/Al photodiode was fabricated and investigated. SnS thin film were prepared by thermal evaporation technique on porous silicon layer which prepared by anodization technique at $32 \mathrm{~mA} / \mathrm{cm}^{2}$ etching current density and etching time $15 \mathrm{~min}$. The characteristics of porous silicon and $\mathrm{SnS}$ were investigated by using $\mathrm{x}$-ray diffraction $\mathrm{XRD}$, atomic force microscopy AFM, Fourier transformation infrared spectroscopy FT-IR.

Dark and illuminated current-voltage I-V characteristics, spectral responsivity, specific detectivity of photodiode were investigated after depositing. Significant improvement in photosensitivity and detectivity of porous silicon photodiode after $\mathrm{SnS}$ deposition on porous silicon was noticed.
\end{abstract}

\section{Introduction}

SnS thin films with band gap energy of $1.3 \mathrm{eV}$ have great potential use in many applications. SnS films are highly suitable for a number of solid state devices, such as photovoltaic [1-5], photo-electrochemical (PEC) [6], photoconductive cells [7], and intercalation battery systems [8]. In addition, SnS thin films have a large optical absorption coefficient $\left(>10^{4} \mathrm{~cm}^{-1}\right)$ and high photoelectric conversion efficiency $(>24 \%$ ) [9] for the fabrication of heterojunction solar cells. Recently, a survey on the ores of tin sulphide have been done by by Reddy et al. [10] indicates that $\mathrm{SnS}$ compound could be used for photovoltaic application as an alternative material. These films can be prepared by different techniques, such as plasma enhanced chemical vapour deposition (PECVD) [11], vacuum evaporation [12], chemical bath deposition [13], spray pyrolysis [14], electrodeposition [15]. In this paper,we report on the preparation and characterization of thermally evaporated SnS thin films on porus silicon PS in order to study their suitability for the device application.

\section{Experimental work}

Samples used in this study are boron doped crystalline silicon (c-Si) wafers (thickness 508 $\pm 15 \mu \mathrm{m}$ and resistivity $1.5-4 \Omega$.cm grown by Czochralski (CZ) method in (100) orientation. . The wafer was first dipped in $10 \%$ HF to remove the native oxide. The back side of the wafer was covered with wax. The porous layer was formed by Photoelectrochemical etching (anodization) in ethanoic hydrofluoric acid solution at a current density of $32 \mathrm{~mA} / \mathrm{cm}$ for $15 \mathrm{~min}$ in dark conditions at $300 \mathrm{~K}$. Ethanol was often added to evacuate the $\mathrm{H}$ bubbles.

High purity (99.99\%) SnS thin film was deposited on the n-PSi substrates by thermal evaporation system type (Edwards) at $10^{-6} \mathrm{mbar}$, thickness $200 \mathrm{~nm}$. The bottom of PSi and above of $\mathrm{SnS}$ electrodes is coated with thick aluminum layer to measure the electrical propertiesas shown in figure 1: 


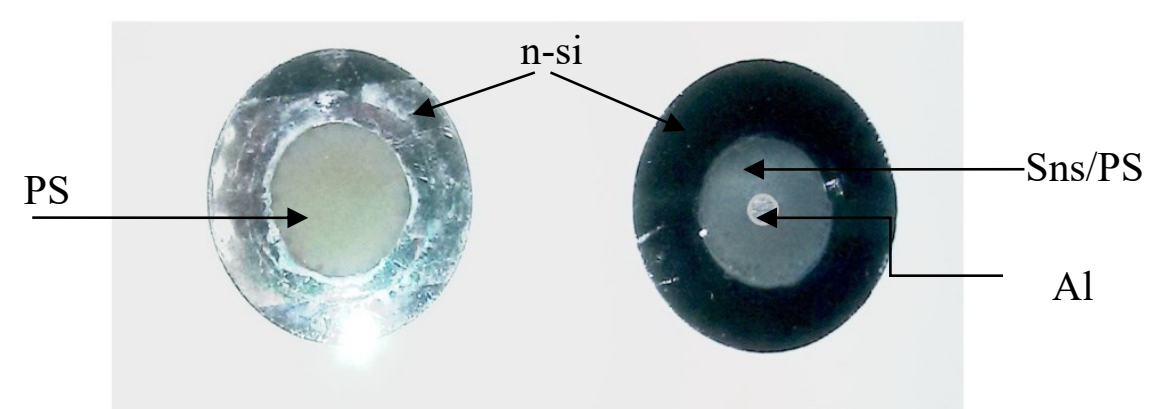

Fig 1: Images for PS/Si and Al/SnS/PS/n-Si/Al photodiede

The structural, morphological and optical properties of porous silicon and SnS were investigated separately by means of $(\mathrm{CuK} \alpha)$ XRD-6000, Shimadzu x-ray diffractometer, Fourier transformation infrared spectroscopy, JEOL (JSM-5600) scanning electron microscopy, Philips CM10 pw 6020 transmission electron microscopy, Angstrom AA 3000 atomic force microscopy and Cary 100 Conc plus UV-Vis spectrophotometer. The spectral photosensitivity of the doped and undoped photodetectors was measured in the range of $400-950 \mathrm{~nm}$ by using a monochromator, and a Sanwa silicon power meter was used for monochromator calibration.For capacity measurements ,a $5 \mathrm{~Hz}-13 \mathrm{MHz}$ impedance analyser was used. The (I-V) measuremements, two electrometers and a $25 \mathrm{~V}$ power supply were used .The spectral responsivity of $A l / S n S / P S / n-S i / A l$ photodiede was investigated by using a monochromator after making power calibration with standdared silicon power meter . All the above characteristics are investigated at room temperature.

\section{Results and discussion}

\section{3. a porous silicon stadies}

Figure 2 shows X-ray diffraction of crystalline silicon and PS samples. A peak of PSi at $32 \mathrm{~mA} / \mathrm{cm}^{2}$ current density shows a splitting peak at $2 \theta=33.5^{\circ}$ oriented only along the (211) direction is observed confirming the monocrystalline structure of the PS layer which belongs to the (211) reflecting plane of Si of cubic structure (according to ICDD N 1997 and 2011 JCPDS).

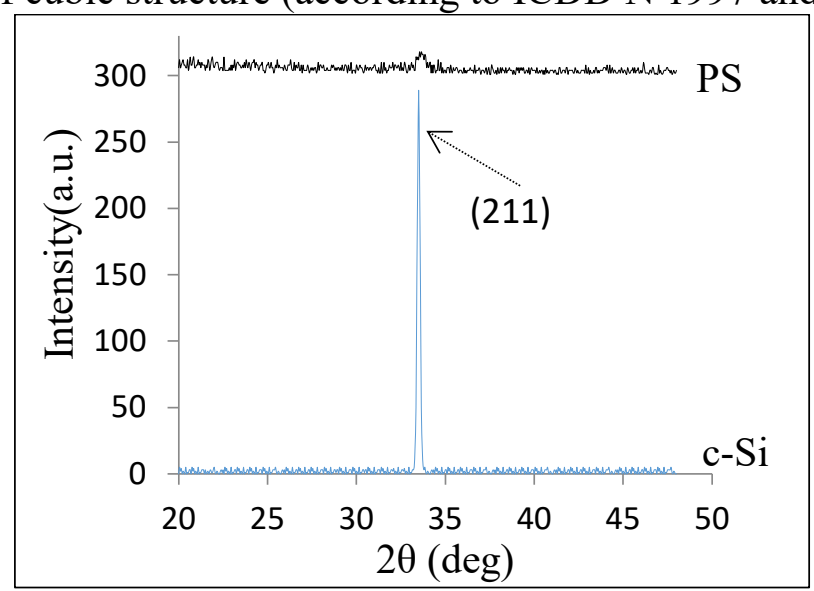

Fig. 2: XRD spectra of c-Si and PSi samples anodized for $15 \mathrm{~min}$ etching time and $32 \mathrm{~mA} / \mathrm{cm}^{2}$ anodization current density.

The intensity of the porous silicon peak decreases when the crystal size is reduced toward nanometric scale, then a broadening of diffraction peaks is observed, as compared with c-Si peak, and the width of the peak is directly correlated to the size of the nanocrystalline domains. This result is ascribed and listed in Table (1). 
Table 1: Calculated crystallite size, average grain size, dislocation density and strain for PSi prepared at 15min etching current .

\begin{tabular}{|c|c|c|c|c|c|}
\hline $\begin{array}{c}\text { Current density } \\
\left(\mathrm{mA} / \mathrm{cm}^{2}\right)\end{array}$ & $\begin{array}{c}2 \Theta \\
(\mathrm{deg})\end{array}$ & $\begin{array}{c}\text { FWHM } \\
(\mathrm{deg})\end{array}$ & $\begin{array}{c}\mathrm{D} \\
(\mathrm{nm})\end{array}$ & $\begin{array}{c}\text { Dislocation density } \\
\left(\text { lines.m }^{-2}\right) \times 10^{14}\end{array}$ & $\begin{array}{c}\text { Strain } \times 10^{-3} \\
\text { lines }^{2} \mathrm{~m}^{-4}\end{array}$ \\
\hline 32 & 33.5 & 0.217 & 39.93 & 6.27 & 9.06 \\
\hline
\end{tabular}

AFM image of PS prepared on n-Si wafer give the formation of uniform porous structures on the silicon wafer. The topographical properties of the PS samples prepared with current density $32 \mathrm{~mA} / \mathrm{cm}^{2}$ at $15 \mathrm{~min}$ etching time are shown in figure (3), which shows 3D images and Granularity accumulation distribution charts of the anodized PS. We can observe from this figure that the avgerage diameter is about $41.08 \mathrm{~nm}$. The surface morphology of the n-PSi layer investigated by the AFM analyses is shown very smooth and homogeneous structures .The average roughness is $0.7 \mathrm{~nm}$ and the RMS is $0.842 \mathrm{~nm}$, while the Porosity equal to $62 \%$.
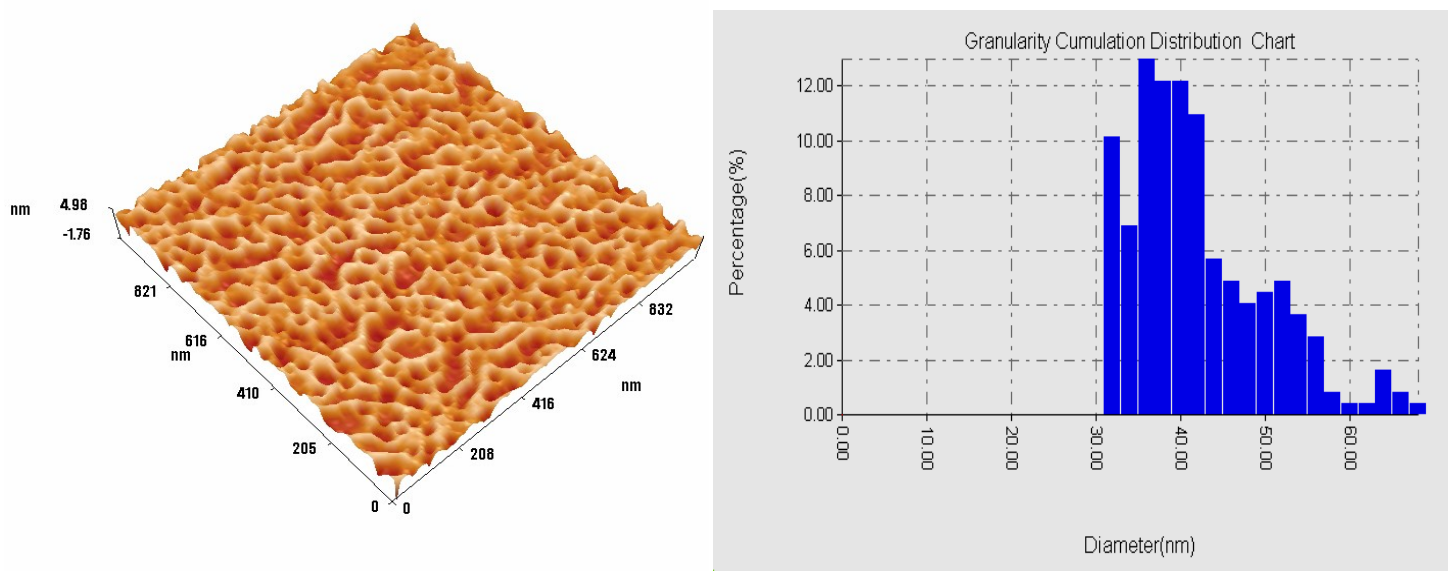

Fig. 3: 3D AFM images of n-PS surface and Granularity accumulation distribution chart of PS prepared at $15 \mathrm{~min}$ and different etching current densities

Surface chemical composition of PSi is best probed with Fourier Transform Infrared (FTIR) spectroscopy. Figure (4) shows the FTIR spectra for PS layer. A strong broad band is observed at about $1071 \mathrm{~cm}^{-1}$ and $1080.17 \mathrm{~cm}^{-1}$ due to Si-O-Si asymmetry stretching vibrations mode in PSi , which are dependent on the oxidation degree of porous silicon. The transmittance peak at 624.94 $\mathrm{cm}^{-1}, 638.46 \mathrm{~cm}^{-1}, 873 \mathrm{~cm}^{-1}, 2088.98 \mathrm{~cm}^{-1}, 2114.05 \mathrm{~cm}^{-1}$ and $2260.65 \mathrm{~cm}^{-1}$ Si-H bending in $\left(\mathrm{Si}_{3} \mathrm{SiH}\right), 908.47 \mathrm{~cm}^{-1} \mathrm{Si}-\mathrm{H}_{2}$ scissor mode. The transmittance peak at $1705.07 \mathrm{~cm}^{-1}$ related to C-O.

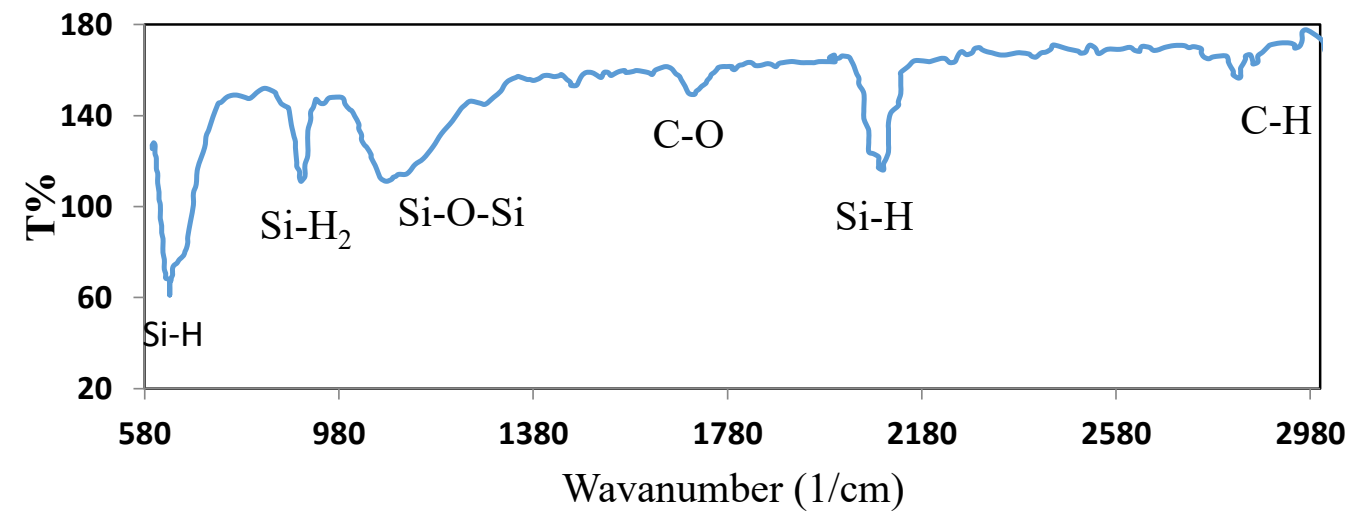

Fig. 4: FTIR spectra of the sample prepared at $15 \mathrm{~min}$ for $32 \mathrm{~mA} / \mathrm{cm} 2$ etching current density. 
PL spectrum of the PSi/p-Si heterojunction formed at the current density $32 \mathrm{~mA} / \mathrm{cm}^{2}$ at $15 \mathrm{~min}$ etching time indicating emission peak 744nm as shown in figure (6), the PL peak are related to the S-band emission, an emission for the fixed excitation wavelength at $380 \mathrm{~nm}$.

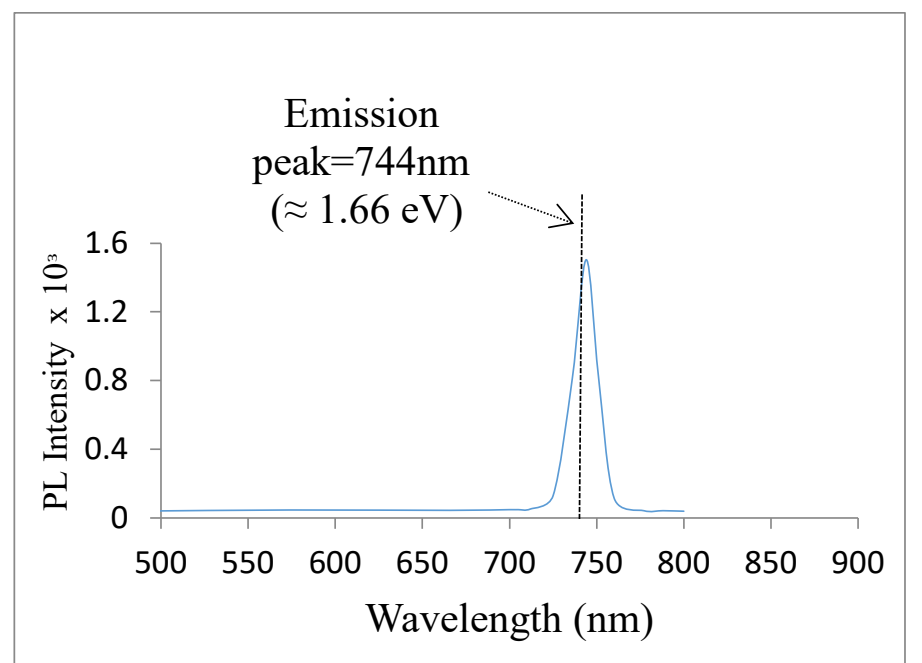

Fig. 5: PL spectra for p-PSi prepared at $15 \mathrm{~min}$ etching time and $32 \mathrm{~mA} / \mathrm{cm}^{2}$ current density.

Increase of current density $32 \mathrm{~mA} / \mathrm{cm}^{2}$ leads to increase the porosity and thereby produces large porous structures, which leads to brighter PL at shorter wavelengths, and this may be attributed to the luminescence from the confined silicon structures. The silicon structure size on the surface clearly decreases by increasing the porosity. Size dependency of the PL energy, which explains the efficient luminescence[10].

\section{3.b SnS thin film studies}

X-ray diffraction patterns of $\mathrm{SnS}$ thin film prepared at at $200{ }^{0} \mathrm{C}$ temperatures are given in Figure 6. The figure shows crystalline peak at $2 \theta=31.6^{\circ}$, corresponding to the (111) plane of orthorhombic crystal structure, compared to JCPDS card 33-1375 for herzenbergite SnS [16]. The spectrum reveal the presence of traces of other phases along with predominant SnS phase. Degree of crystallinity was also found at $200{ }^{\circ} \mathrm{C}$ temperature. The XRD spectrum of films grown at lower $200{ }^{\circ} \mathrm{C}$ temperatures showed presence of both $\mathrm{SnS}_{2}$ and $\mathrm{Sn}$ phases, along with dominant SnS phase.

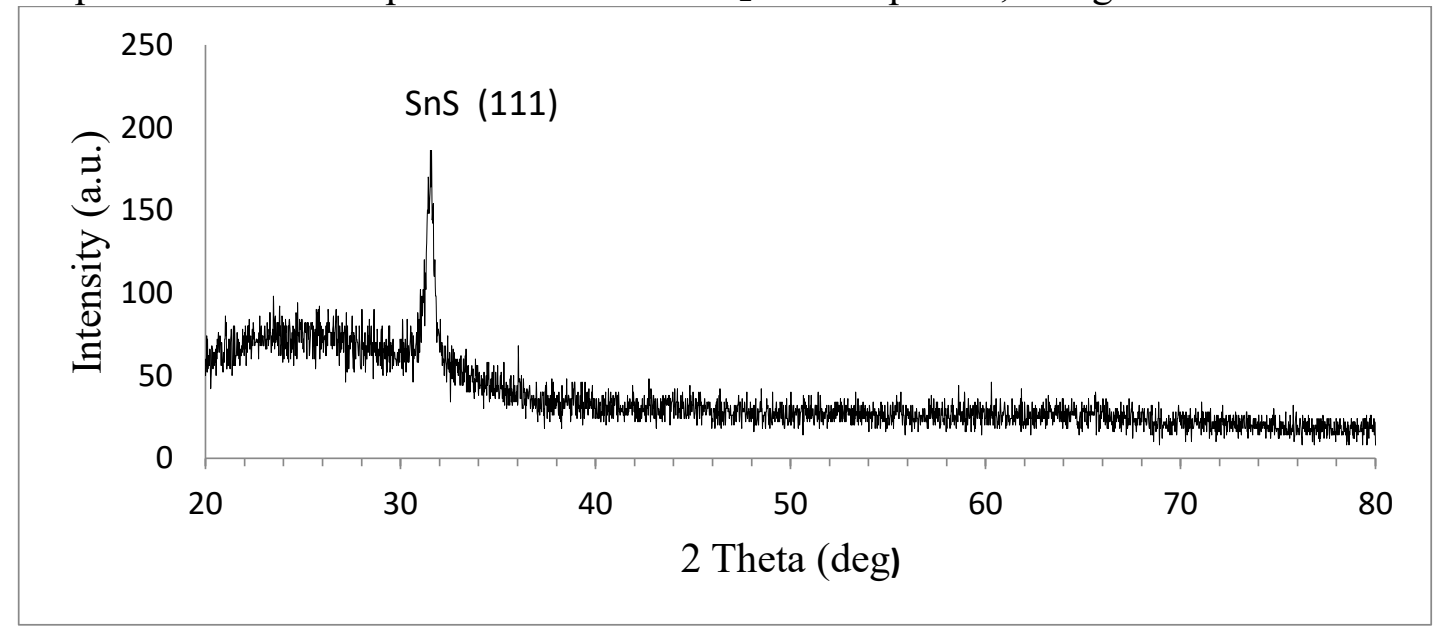

Fig. 6: XRD spectra of SnS thin film.

The SnS films deposited on glass by thermal avaporation and annealed at $200{ }^{\circ} \mathrm{C}$. XRD spectra releave the the surface has a good crystallanity. The height of (111) peak in X-ray diffraction pattern for $\mathrm{SnS}$ thin films prepared at annealing temperature of $200{ }^{\circ} \mathrm{C}$ are found to have sharper peaks with small FWHM data.The average crystallite size has been calculated the Debye-Scherrer formula [16]: 


$$
D=\frac{0.9 \lambda}{\beta \cos \theta}
$$

where $D$ is the mean crystallite size, $\beta$ is the full width at half maximum (FWHM) of the diffraction line , $\theta$ is the diffraction angle, and $\lambda$ is the wavelength of the $\mathrm{X}$-ray radiation. The dislocation density $\delta$ can be evaluated from Williamson and Smallman's formula, $\delta\left[1\right.$ ines $\left./ \mathrm{m}^{2}\right]$ :

$$
\sigma=\frac{1}{D^{2}}
$$

The microstrain $\varepsilon$ can be obtained using the relation:

$$
\varepsilon=\frac{\beta \cos \theta}{4}
$$

The crystallite size, dislocation density and microstrain were $65.44 \mathrm{~nm}, 2.3 \times 10^{14}\left(\right.$ lines $\left./ \mathrm{m}^{2}\right)$ and $18.56 \times 10^{-4}$ respectively .

The SEM picture of SnS thin film deposited at $200{ }^{\circ} \mathrm{C}$ for $1 \mathrm{~h}$ is shown in Figure 7 . It was seen that the film had a needle shape grain structure without cracks on the surface. The grains crystallization was relatively good, grain sizes were almost near and the surface was uniformly covered. Surface properties observed have a strong effect on the optical properties of the thin film such as transition, absorption, and reflection. When such a surface morphology is formed on the surface of gas sensor or solar cell, it provides an extensive surface area for reaction[7].

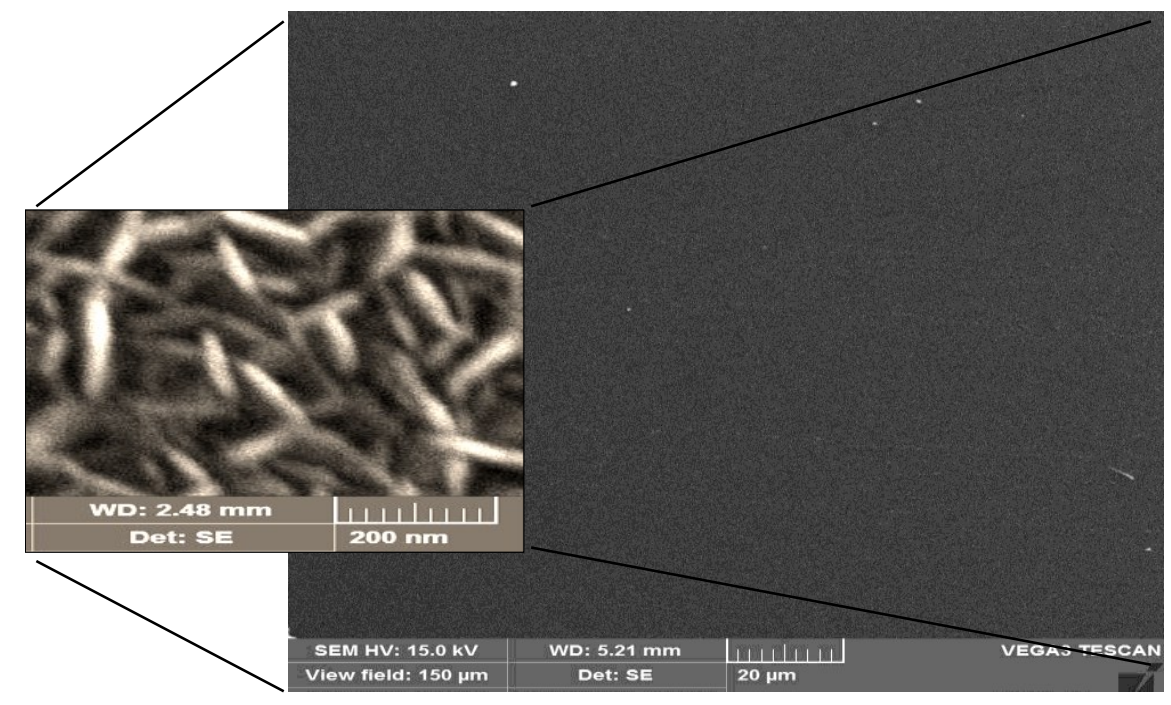

Fig.7 : SEM micrograph of SnS thin film.

Figure 8 shows AFM images of $\mathrm{SnS}$ thin film deposited on glass substrate at $200{ }^{\circ} \mathrm{C}$. The $\mathrm{SnS}$ film shows a granular morphology with good pyramid-like crystal structure and tightly bonded well formed dense network. These grains are oriented uniformly with nearly equal size. The composition analysis of the $\mathrm{SnS}$ film showed that the average diameter ,roughness density and RMS were 55 $\mathrm{nm}, 0.534 \mathrm{~nm} 0.556 \mathrm{~nm}$ respectively.
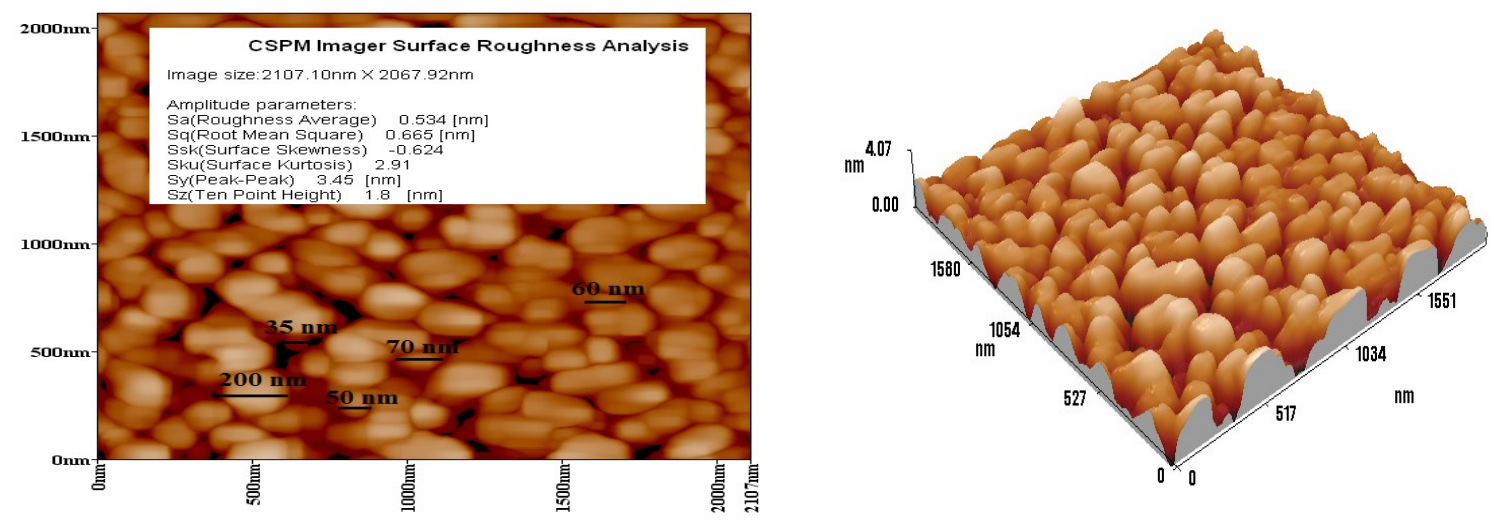

Fig. 8: 2D and 3D AFM images of SnS thin film . 
Hall meusherments that releave that the resistivity for the deposited SnS films have high resistivity. However, we managed to obtain resistivity of the sample, which is $4.02 \times 10^{5} \Omega \mathrm{cm}$. It is much higher than the resistivity for solar cell applications, which ideally should be around (1$10) \Omega \mathrm{cm}$.

The values of optical transmittance in the range from $300-900 \mathrm{~nm}$ and a plot of $(\alpha \mathrm{hv})^{2}$ against (hv) of SnS thin film were used to obtain direct band gap values. Figure (9) showed an increase in indirect band gap of $\mathrm{SnS}$ thin films. We conclude that the concentration of complexing agents has the effect on direct band gaps as they control the rate of release of $\mathrm{Sn}^{2+}$ ions and hence modify the structura properties.

The deposited $\mathrm{SnS}$ film had shown high absorption coefficient, $>10^{5} \mathrm{~cm}^{-1}$, above the fundamental absorption edge. Single phase $\mathrm{SnS}$ thin films deposited at $200{ }^{\circ} \mathrm{C}$ have shown the presence of direct optical band gap at $2.4 \mathrm{eV}$. These nearly stoichiometric, single-phase and highly absorbing SnS films with a direct optical band gap of $1.36 \mathrm{eV}$ could be used as an absorber in the fabrication of thin film heterojunction photovoltaic devices.

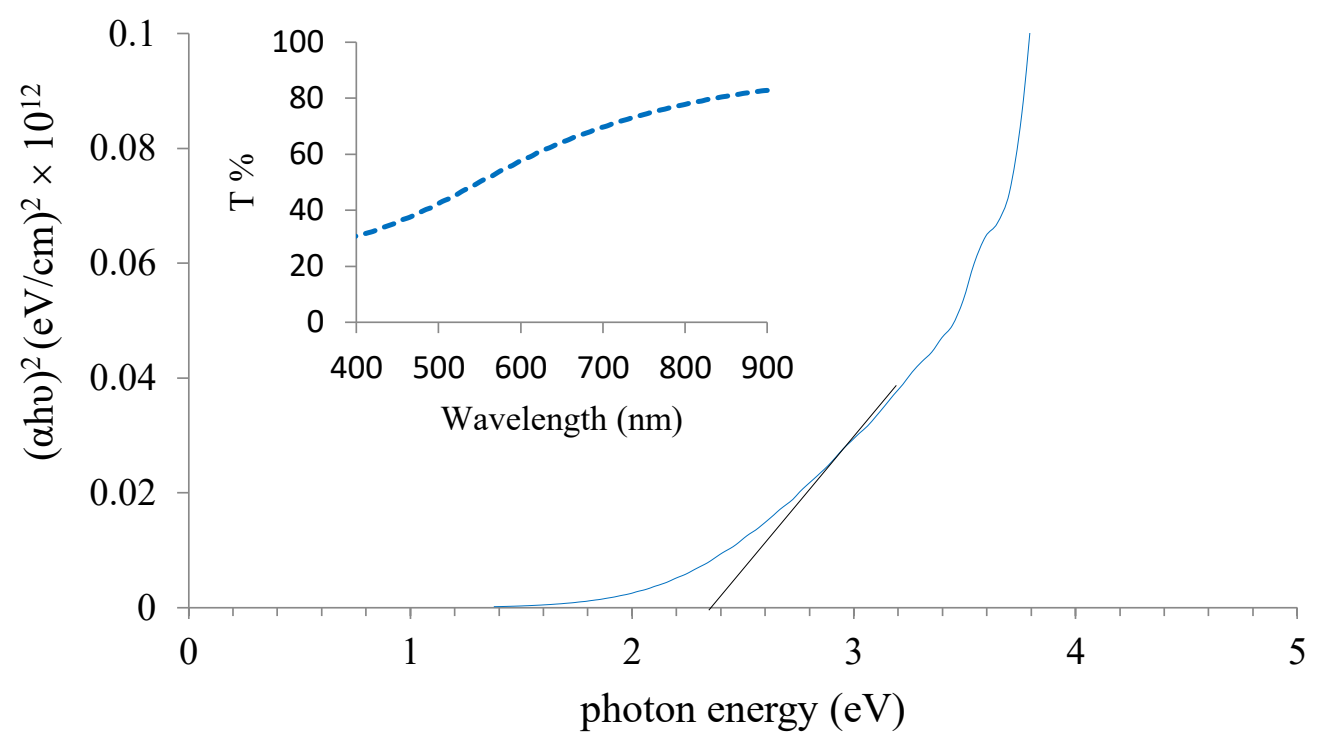

Fig. 9: $(\alpha h v)^{2}$ versus photon energy plot and inset is transmission spectrum of SnS thin film.

\section{3.c Al/SnS/PS/n-Si/Al Photodetector Properties}

Figure 10 shows the dark current-voltage (I-V) characteristics in forward and reverese direction of $\mathrm{Al} / \mathrm{SnS} / \mathrm{PS} / \mathrm{n}-\mathrm{Si} / \mathrm{Al}$ and $\mathrm{Al} / \mathrm{PS} / \mathrm{n}-\mathrm{Si} / \mathrm{Al}$ photodieodes . The current in forwared direction has increasd after deposited SnS thin film due to increase the charge which transfer between PS layer and $\mathrm{Al}$ electrode .

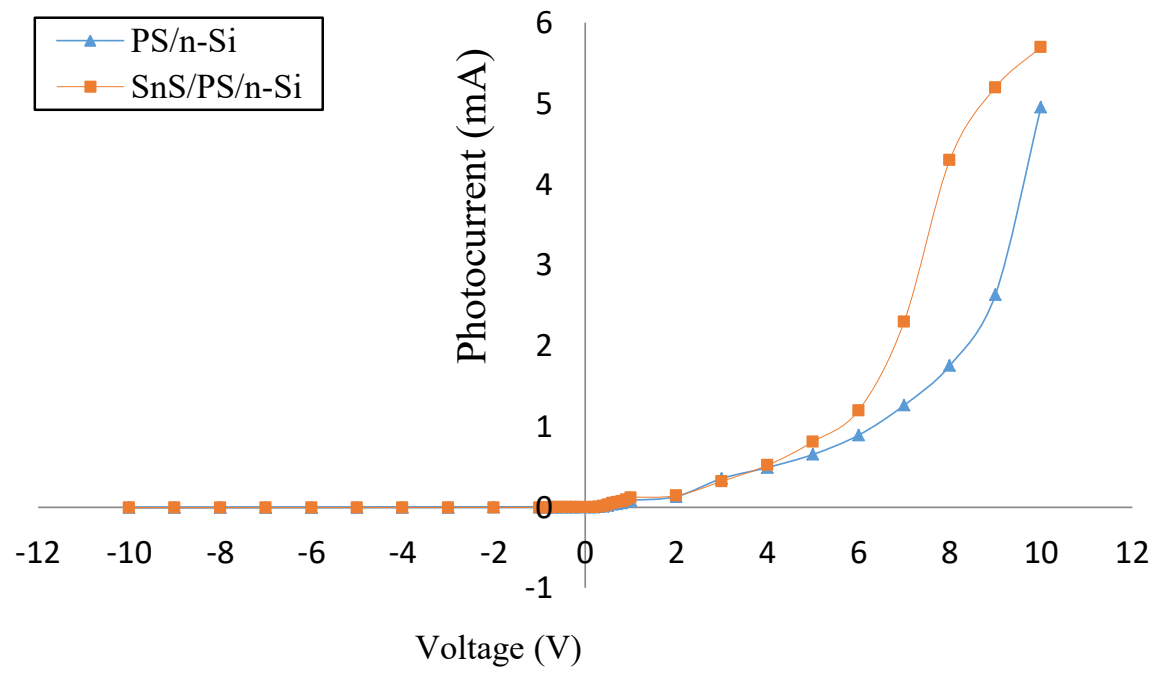

Fig. 10: Dark I-V characteristics of Al/SnS/PS/n-Si/Al and Al/ PS/n-Si/Al photodieodes 
Figure 11 shows the dark (I-V) characteristics in reverese direction of $\mathrm{Al} / \mathrm{SnS} / \mathrm{PS} / \mathrm{n}-\mathrm{Si} / \mathrm{Al}$ and $\mathrm{Al} /$ $\mathrm{PS} / \mathrm{n}-\mathrm{Si} / \mathrm{Al}$ photodieodes under $8 \mathrm{~mW} / \mathrm{cm}^{2}$ ligth illumination. The photocurrent in revrese direction has increasd after deposited $\mathrm{SnS}$ thin film due to increase the increase of absorption coefficient and carriers diffusion length [17] of the photo -induced carriers from $\mathrm{SnS}$ thin film to PS.

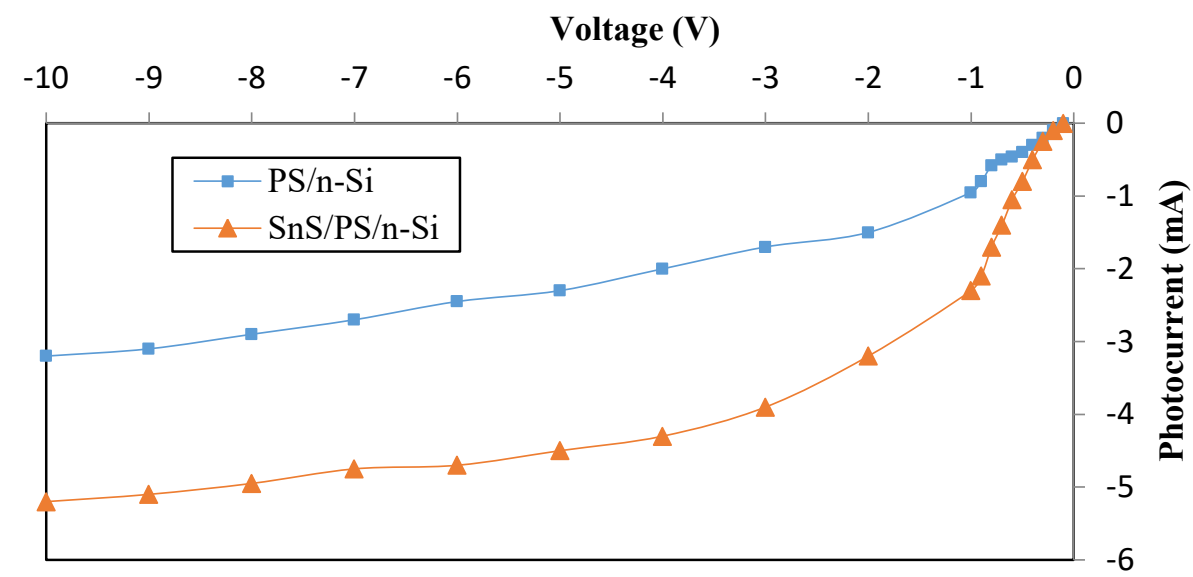

Fig. 11: Illuminated I-V characteristics of $\mathrm{Al} / \mathrm{SnS} / \mathrm{PS} / \mathbf{n}-\mathrm{Si} / \mathrm{Al}$ and $\mathrm{Al} / \mathrm{PS} / \mathbf{n}-\mathrm{Si} / \mathrm{Al}$ photodieodes.

Figure 12 shows a linear relation between inverce of sequare of capacitance $\left(1 / \mathrm{C}^{2}\right)$ reverce bias voltage for $\mathrm{Al} / \mathrm{PS} / \mathrm{n}-\mathrm{Si} / \mathrm{Al}$ and $\mathrm{Al} / \mathrm{SnS} / \mathrm{PS} / \mathrm{n}-\mathrm{Si} / \mathrm{Al}$,indicating abrupt junction .The bult -in potential $\mathrm{V}_{\mathrm{b}}$ value were obtained after exrtrapolating the $\left(1 / \mathrm{C}^{2}\right)$ point to the voltage axis. The bult -in potential $\mathrm{V}_{\mathrm{b}}$ for PS/n-si was 1.1 volt but it was decreadsed to the 0.3 volt for $\mathrm{SnS} / \mathrm{PS} / \mathrm{n}-\mathrm{Si}$. The value of $\mathrm{V}_{\mathrm{b}}$ are expected to depond on the Fermi level position in the conduction band at high concentrations for $\mathrm{SnS}$ thin film and this behavior is attributed to the increasing of depletion region width, leading to the decrease the capacitance at the junction sides.

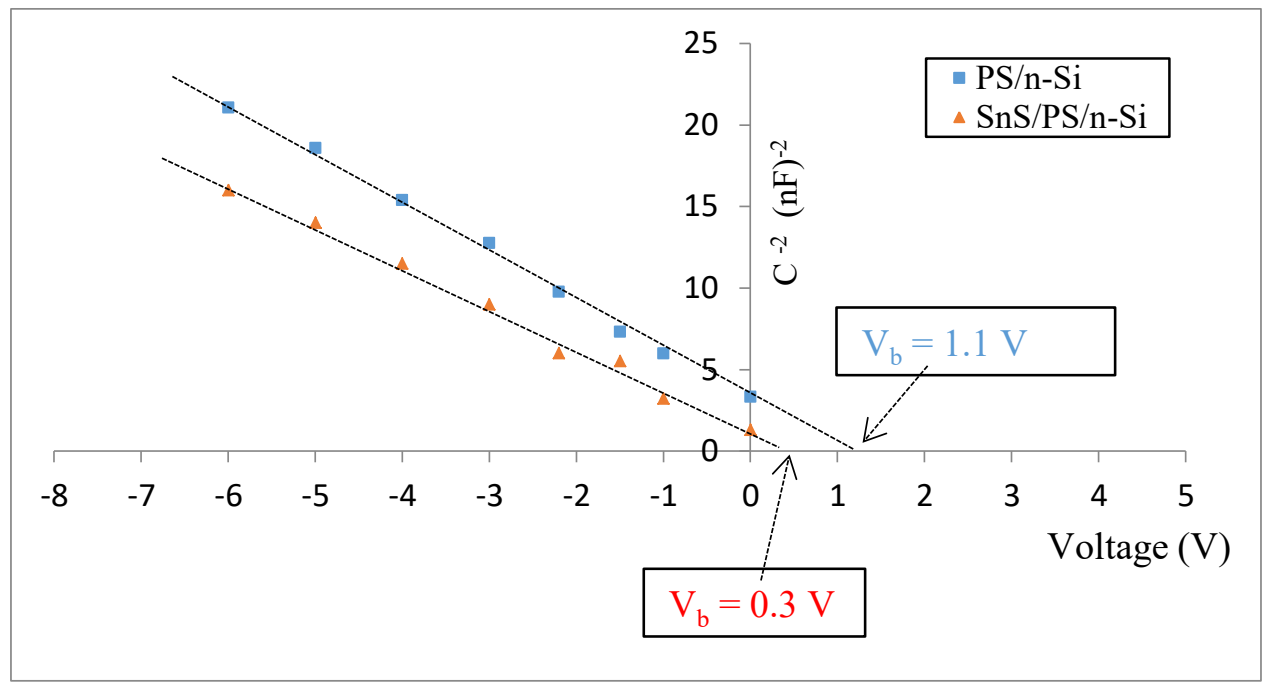

Fig. $12: 1 / C^{2}$ versus reverse voltage of $\mathrm{Al} / \mathrm{SnS} / \mathrm{PS} / \mathrm{n}-\mathrm{Si} / \mathrm{Al}$ and $\mathrm{Al} / \mathrm{PS} / \mathrm{n}-\mathrm{Si} / \mathrm{Al}$ photodieodes.

Figure 13 shows the spectral responsivity and spectral detectivity (inset) of $\mathrm{Al} / \mathrm{SnS} / \mathrm{PS} / \mathrm{n}$ $\mathrm{Si} / \mathrm{Al}$ photodieode is investigated in the wavelength rang from $400 \mathrm{~nm}$ to the $900 \mathrm{~nm}$ with 5 volt bais, which is calculated by fellowing equation :

$$
R_{(\lambda)}=\frac{I_{p h}}{p_{\text {in }}}
$$

Where $\mathrm{I}_{\mathrm{ph}}$ is the photocurrent and $\mathrm{p}_{\mathrm{in}}$ is the input power

The spectral responsivity is an important function to know how mach detector signal will be available for application [18] . 


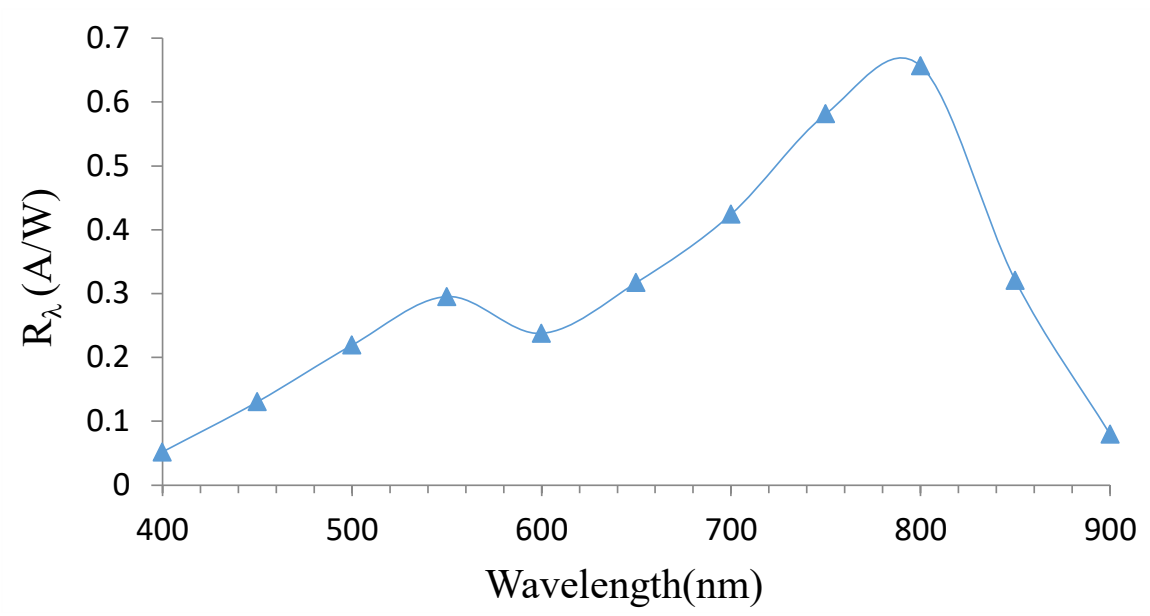

Fig. 13: Spactlar responsivity as a function of wavelength of $\mathrm{SnS} / \mathrm{PSi} / \mathrm{n}-\mathrm{Si}$ photodiode .

The $\mathrm{SnS} / \mathrm{PS} / \mathrm{n}-\mathrm{Si}$ sandewich structure (photodieode) has two peaks located at about $550 \mathrm{~nm}$ represented the absorption edge of $\mathrm{SnS} / \mathrm{PS}$ as shown in figure 14(a) and the other one located at $750 \mathrm{~nm}$ related to the PS/n-Si as in figure 14(b)
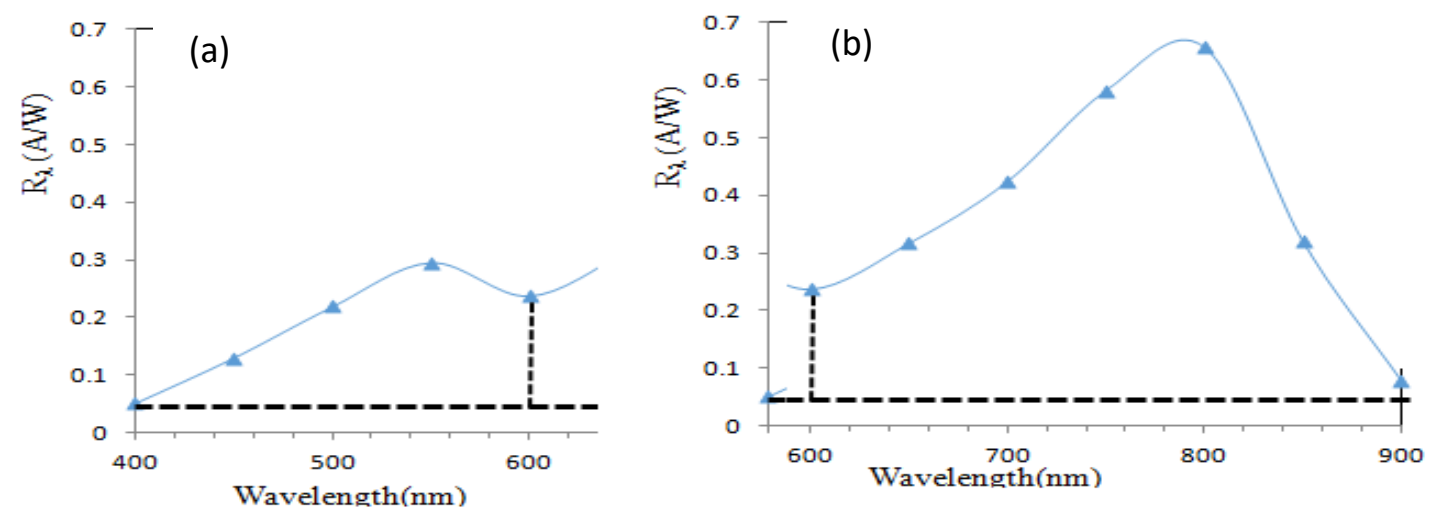

Fig. 14: Spactlar responsivity as a function of wavelength of $\mathrm{SnS} / \mathrm{PSi} / \mathrm{n}-\mathrm{Si}$ photodiode,(a) the absorption edge of SnS/PS and (b) the absorption edge of PS/n-Si .

Figure 15 shows spectral detectivity as afunction of wavelength $(400 \mathrm{~nm}-900 \mathrm{~nm})$.this figure shows that it is deponded directly to the spectral responsivity and calculated by the following equation [18]:

$$
\begin{gathered}
D_{(\lambda)}=R_{(\lambda)}\left(\frac{A^{.1 / 2} \Delta f^{1 / 2}}{I_{n}}\right) \\
I_{n}=\sqrt{2 q I_{d} \Delta f}
\end{gathered}
$$

where $\Delta f$ is the noise bandwidth, $I_{n}$ is the noise current and $A$ is the erea of the detector. A detectivity of photodiode is about $9.8 \times 10^{12} \mathrm{~cm} . \mathrm{Hz}^{-1} . \mathrm{W}^{-1}$ at $793 \mathrm{~nm}$ was obtained when detector was biased to $-5 \mathrm{~V}$

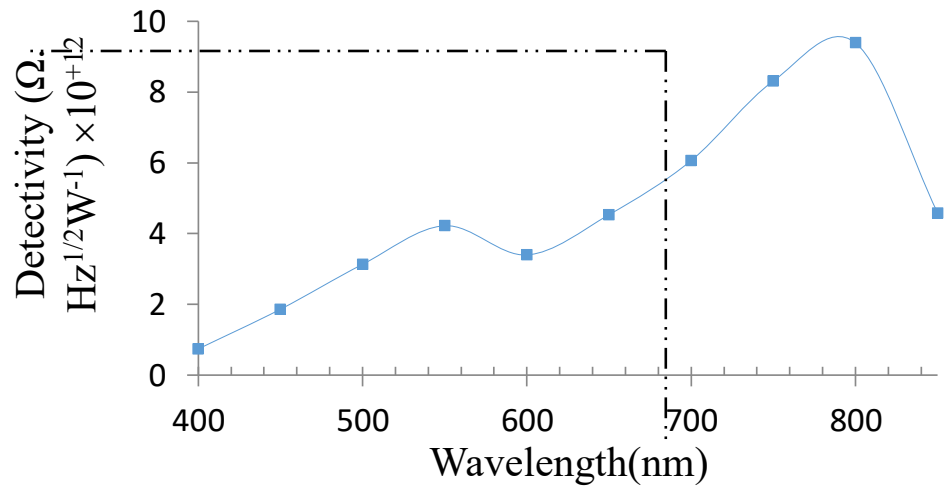

Fig. 15: Spactlar detectivity as a function of wavelength of SnS/PSi/n-Si photodiode . 


\section{Conclusion}

A simple and efficient approach to omprove the photo-detective of poroud silicon PS prepared by potoelectrochimical method via deposited SnS layer on PS by thermal evaporation technique.

Deposition of $\mathrm{SnS}$ on porous silicon (PS) gives suspensions photodetector characteristics enhanced the properties porous photodetectors and the spectral responsivity $\mathrm{R}_{(\lambda)}$ of $\mathrm{Al} / \mathrm{SnS} / \mathrm{PS} / \mathrm{n}$ $\mathrm{Si} / \mathrm{Al}$ photodetector is around $0.7 \mathrm{~A} / \mathrm{W}$ at $\approx 750 \mathrm{~nm}$ wavelength due to the absorption edge of silicon and around $0.3 \mathrm{~A} / \mathrm{W}$ at $\approx 400 \mathrm{~nm}$ wavelength due to the absorption edge of SnS thin film . The maximum value of the specific detectivity $\mathrm{D}_{(\lambda)}$ is found to be $9.8 \times 10^{12} \mathrm{~W}^{-1} \mathrm{~cm} \cdot \mathrm{Hz}^{-1}$ located at $793 \mathrm{~nm}$ wavelength for $\mathrm{Al} / \mathrm{SnS} / \mathrm{PSi} / \mathrm{Si} / \mathrm{Al}$ photodetector prepared by $32 \mathrm{~mA} / \mathrm{cm}^{2}$ current density for 15 min aching time and the SnS thin film .

\section{References}

[1] Ramakrishna Reddy K. T., K oteswara Reddy N., , Miles R.W., Photovoltaic properties of SnS based solar cells, Solar Energy Materials and Solar Cells, 90(2006)3041-3046.

[2] Albers W., Haas C., Vink H.J., Wasscher J.D., Investigations on SnS, Journal of Applied Physics 32, 10,(1961) 2220-2225.

[3] Nikolic P.M., Todorovic D.M., Photo-acoustic and thermo-acoustic properties of single-crystal SnS compared with its near-infrared optical and transport measurements, Journal of Physics C: Solid State Physics 20,1(1978) 39-44.

[4] Ghosh B., Royr., Chowdhury S., Banerjeep P., DAS S., Synthesis of SnS thin films via galvanostatic electrodeposition and fabrication of $\mathrm{CdS} / \mathrm{SnS}$ heterostructure for photovoltaic applications, Applied Surface Science 256,13 (2010) 4328-4333.

[5] Sharon M., Basavawaran K., Photoelectrochemical studies on p-SnSe electrodes, Solar Cells 20,4(1978) 323-332.

[6] Blaesser G., Rossi E., Extrapolation of outdoor measurements of PV array I-V characteristics to standard test conditions, Solar Cells 25,2(1988) 91-96.

[7] Kawano K., Nakata R., Sumita M., Effects of substrate temperature on absorption edge and photocurrent in evaporated amorphous $\mathrm{SnS}_{2}$ films, Journal of Physics D: Applied Physics 22,1(1989) 136-140.

[8] Whittingham M.S., Jacobsen A.J., [Eds.], Intercalation Chemistry, Academic Press, New York,(1982).

[9] Yue G.H., Wang W., Wang L.S., Wang X., Yan P.X., Chen Y., Peng D.L., The effect of anneal temperature on physical properties of $\mathrm{SnS}$ films, Journal of Alloys and Compounds 474,1-2 (2009) 445-449.

[10] Koteeswara Reddy N., Ramakrishna Reddy K.T., Preparation and characterisation of sprayed tin sulphide films grown at different precursor concentrations, Materials Chemistry and Physics 102,1(2007) 13-18.

[11] Oritz A., Alonso J.C., Garica M., Toriz J., Tin sulphide films deposited by plasmaenhanced chemical vapour deposition, Semiconductor Science and Technology 11,2(1996) $243-247$.

[12] Ghosh B., Das M., BanerjeeA P., DAS S., Fabrication of vacuum-evaporated SnS/CdS heterojunction for PV applications, Solar Energy Materials and Solar Cells 92.9(2008) 10991104. 
[13] Avellaed D., Nair M.T.S., Nair P.K., Polymorphic tin sulphide thin films of zinc blende and orthorhombic structures by chemical deposition, Journal of the Electrochemical Society $\mathbf{1 5 5 , 7 ( 2 0 0 8 ) 5 2 5}$

[14] Koteswara Reddy N., Ramakrishna Reddy K.T., Growth of polycrystalline SnS films by spray pyrolysis, Thin Solid Films 325,1-2(1998)4-6.

[15] Sato N., Ichimura M., Arai E., Yamazaki Y., Characterization of electrical properties and photosensitivity of SnS thin films prepared by the electrochemical deposition method, Solar Energy Materials and Solar Cells 85,2(2005) 153-165.

[16]. Scherrer, P.,Gottinger Nachrichten Gesell,2(1918) 98.

[17] Nadir F.H, Raid A.Ismail, Ahmed N Abd, Improved photoresponce of porous silicon photodetector by embedding CdSe nanoparticles, Indian Journal of pure \&Applied Physics ,53(2015)718-724.

[18] Sugaki A., Kitakaze A., KitazawaI H., Synthesized tin and tin-sulfide minerals; Synthetic sulfide inerals (XIII), Science Reports of the Tohoku University 16,3(1985) 199-211 